\title{
The Effect of Participation in a University-Community Linked Class on Skeletal Muscle and Balance of Elderly Individuals Living Alone
}

\author{
Young Hee Cho ${ }^{1}$ \\ ${ }^{1}$ Professor, Sport Education, Kookmin University, Korea, choyh@kookmin.ac.kr
}

\begin{abstract}
As the elderly population in Korea increases, the number of elderly living alone increases, as is their loneliness and depression. Their ability to live independently correlates with a better quality of life. This study was aimed to determine whether participation in university-community linked classes improves skeletal muscle and balance related to daily life and fall prevention among the elderly living alone. The subjects were 11 elderly living alone at a welfare center. The universitycommunity linked class lasted 15 weeks: 3 weeks of lesson plans, preparation, feedback from students and professor of B university, and mock classes. There were 12 weeks of mock classes (with Review Report_actual classes and self-assessment for the elderly in the welfare center, moderate-intensity newsports at 60 minutes once per week, and flexibility and strength-based home training for five times per week). The collected data were analyzed using IBM SPSS Statistics 25. Furthermore, descriptive statistics (Wilcoxon's signed-ranks test, and Spearmen correlation, a nonparametric test method) were used. The study results were as follows: first, skeletal muscle mass, upper and lower body muscle strength improved, and the vestibular sensory system (balance) improved; second, there was a positive correlation between balance using the visual system and lower body muscle strength. There was a positive correlation between upper body muscle strength when holding balance with the right foot using the visual and somatosensory systems. There was also a significant positive correlation between vestibular sensation and skeletal muscle mass. In conclusion, the university-community linked class improved physical parameters in the elderly subjects who lived alone. This suggested the necessity of continuously linked-class as it can bring about fall prevention and activities of daily living.
\end{abstract}

Keywords: University-community Linked Class, Skeletal Muscle, Balance, Elderly Individuals Living Alone

\section{Introduction}

The Republic of Korea is an aging society with $14.0 \%$ of the population aged 65 or older as of August 2017; the population of the elderly continues to increase to $16.4 \%$ as of 2021 , and Korea is expected to become a super-aged society by over $20 \%$ in 2025[1]. Life expectancy in 2050 is projected to be 88.2 years old ( 90.1 years old for women, 86.2 years old for men). As of 2020, the average life expectancy was 6 years higher than 83.2 years old (women: 86.1 years old, men 80.3 years old)[2].

New concepts are emerging. 'Centenarians' are those who live over 100 years, and 'Supercentenarians' are those who survive over 110 years. As the elderly population and life expectancy increase, the number of older adults who have difficulty in daily life due to diseases, dementia, and social changes caused by nuclear families increase accordingly. The increase in dual-

Received: December 11, 2020; $1^{\text {st }}$ Review Result: January 25, 2021; $2^{\text {nd }}$ Review Result: March 15, 2021 Accepted: April 30, 2021 
income households, low birth rates, and women's participation in society make it difficult for the elderly to acquire long-term care and care.

Because elderly health is related to the quality of life, to achieve healthy aging, it is essential not only for government efforts but also for personal health care needs to improve. In Korea, the proportion of elderly living alone doubled in 2019 from 2000[3], concurrent with decreases in nuclear family size, birthrates, and support for the elderly. Currently, public health centers are trying to provide customized health care services for the elderly. The average age of service recipients is over 75 , their self-management ability is minimal, and they show economic difficulties and depression. Of these elderly, 96\% have chronic diseases, and their quality of life decreases significantly if they report pain in the musculoskeletal system[4]. With age, physical, social, and psychological aging causes musculoskeletal pain and decreases in muscles, leading to limitations in daily living. For the elderly individuals living alone, activities of daily living such as dressing and undressing, mobility, and washing alone are essential for survival. Muscle loss is associated with various health problems. In 2016, the first disease code for sarcopenia was given in the United States. The World Health Organization (WHO) added sarcopenia as a disease name to the International Classification of Diseases (ICD-11). It is said that sarcopenia decreases the ability to perform activities of daily living, and can increase the incidence of fractures and falls, depression[5], obesity, type 2 diabetes, disability, and death[6].

The elderly require self-management to achieve healthy aging. The present study involves a 1:1 matching exercise program to motivate the elderly to exercise with students at B University College of Physical Education. The university-community linked class conducted in this study aimed to improve multi-sensory balance and skeletal muscles related to falls for the safety of daily life of the elderly by consisting newsports.

Currently, there are few senior exercise programs linked to university communities, and in many cases, they consist of one-off events. Therefore, to analyze the effect of continuous universitycommunity-linked classes, the following research problems were constructed. First, the differences in skeletal muscle and balance (visual, somatosensory, and vestibular sensory systems) of elderly individuals living alone who participated in university-community linked class are investigated. Second, It was examined the correlation between skeletal muscle and balance of elderly people living alone who participated in university-community linked class.

In this study, newsports were applied as main exercise. Newsports refers to participant-centered experiential sports. It is characterized by being easy to perform, with participation modified according to the level and condition of the participant (the activities include T-ball, bolo-ball, flying disc, ground golf, and park golf). Participation in newsports activities among the elderly can generate satisfaction associated with participation and leisure[7]. In the present study, I would like to suggest the effects of university-community linked to newsports and daily home training.

\section{Research Method}

\subsection{Subject Characteristics}

The subjects of this study were the elderly (over 70 years) living alone. The exercise consisted of newsports designed to improve balance, coordination, strength, and aerobic capacity. Students and the elderly subjects participated once per week at a welfare center; there was also home training for flexibility, strength for seniors five times per week.

The physical fitness of 11 older adults was measured using the Senior Fitness Test[8]. The physical characteristics of the elderly are shown in [Table 1]. The average age was 83.4 years, and the average height was $151.3 \mathrm{~cm}$. Based on the average age of 83.4 years, mean values for fitness test results were 
as follows: lower body strength (the number of times to stand up from a chair for 30 seconds) was 11.9 (the normal range); upper body strength (the number of arm bends with $2.5 \mathrm{~kg}$ dumbbells for 30 seconds) was 16.8 (normal range +); cardiorespiratory endurance (the number of steps in place for 2 minutes) was 85.5 (the normal range), and lower body flexibility (sitting and extending both arms forward) was $5.2 \mathrm{~cm}$ (normal range +). Lower body flexibility showed promising results. Upper body flexibility (overlapping the middle finger on the back of the hand) was -6.6 (not good), and agility and dynamic balance (walking and returning at $2.4 \mathrm{~m}$ ) were 9.3 seconds (not good); that is, the elderly participating in this study required upper body flexibility, agility, and dynamic balance.

[Table 1] Physical Characteristics of Subjects

\begin{tabular}{|c|c|c|c|c|c|c|c|c|c|c|c|}
\hline \multirow[b]{2}{*}{$\mathrm{N}$} & \multirow[b]{2}{*}{ Age } & \multirow[b]{2}{*}{$\begin{array}{c}\text { Gender } \\
\text { (Female/ } \\
\text { Male) }\end{array}$} & \multirow[b]{2}{*}{$\begin{array}{l}\text { Height } \\
(\mathrm{cm})\end{array}$} & \multirow[b]{2}{*}{ Disease } & \multicolumn{6}{|c|}{ Physical Fitness } & \multirow[b]{2}{*}{$\begin{array}{c}\text { Recommended } \\
\text { Exercise }\end{array}$} \\
\hline & & & & & $\begin{array}{l}\text { Lower } \\
\text { body } \\
\text { strength } \\
\text { (times) }\end{array}$ & $\begin{array}{l}\text { Upper } \\
\text { body } \\
\text { strength } \\
\text { (times) }\end{array}$ & $\begin{array}{c}\text { Cardio- } \\
\text { respiratory } \\
\text { endurance } \\
\text { (times) }\end{array}$ & $\begin{array}{c}\text { Lower } \\
\text { body } \\
\text { flexibility } \\
(\mathrm{cm})\end{array}$ & $\begin{array}{c}\text { Upper } \\
\text { body } \\
\text { flexibility } \\
(\mathrm{cm})\end{array}$ & $\begin{array}{c}\text { Agility, } \\
\text { dynamic } \\
\text { balance } \\
\text { (sec.) }\end{array}$ & \\
\hline A & 77 & $\mathrm{~F}$ & 161 & $\begin{array}{c}\text { High blood pressure, } \\
\text { diabetes }\end{array}$ & 10 & 13 & 61 & 3 & -4 & 8.9 & $\begin{array}{l}\text { Lower body } \\
\text { strength, } \\
\text { balance }\end{array}$ \\
\hline B & 82 & $\mathrm{~F}$ & 144.5 & $\begin{array}{c}\text { High blood pressure, } \\
\text { diabetes }\end{array}$ & 11 & 13 & 88 & 0 & -3 & 10.5 & Balance \\
\hline $\mathrm{C}$ & 80 & $\mathrm{~F}$ & 142 & $\begin{array}{c}\text { High blood pressure, } \\
\text { diabetes }\end{array}$ & 12 & 15 & 105 & 4.8 & -7 & 8.9 & $\begin{array}{l}\text { Upper body } \\
\text { flexibility }\end{array}$ \\
\hline $\mathrm{D}$ & 78 & $\mathrm{~F}$ & 157 & $\begin{array}{c}3 \text { years after cancer } \\
\text { surgery }\end{array}$ & 11 & 16 & 80 & 2 & -5 & 9 & Balance \\
\hline $\mathrm{E}$ & 86 & $\mathrm{~F}$ & 143 & $\begin{array}{c}\text { High blood pressure, } \\
\text { low back pain }\end{array}$ & 11 & 15 & 70 & 5 & -20 & 11.5 & $\begin{array}{l}\text { Upper body } \\
\text { flexibility, } \\
\text { balance }\end{array}$ \\
\hline $\mathrm{F}$ & 85 & $\mathrm{~F}$ & 148 & High blood pressure & 12 & 19 & 98 & 0 & -10 & 7.3 & Keep \\
\hline $\mathrm{G}$ & 91 & $\mathrm{~F}$ & 156 & $\begin{array}{c}\text { High blood pressure } \\
\text { kidney disease }\end{array}$ & 13 & 24 & 100 & 19 & -23 & 10.3 & $\begin{array}{l}\text { Upper body } \\
\text { flexibility }\end{array}$ \\
\hline $\mathrm{H}$ & 88 & $\mathrm{~F}$ & 145.4 & $\begin{array}{c}\text { High blood pressure, } \\
\text { low back pain }\end{array}$ & 10 & 13 & 90 & 16.8 & 2 & 10.5 & Balance \\
\hline I & 77 & $\mathrm{~F}$ & 154 & $\begin{array}{c}\text { Stroke, } \\
\text { left ankle surgery }\end{array}$ & 13 & 24 & 86 & 2 & -12 & 5.9 & $\begin{array}{l}\text { Upper body } \\
\text { flexibility }\end{array}$ \\
\hline $\mathrm{J}$ & 89 & $\mathrm{~F}$ & 155 & - & 17 & 19 & 74 & 3 & 3 & 8.5 & Keep \\
\hline $\mathrm{K}$ & 84 & $\mathrm{~F}$ & 158 & - & 11 & 14 & 88 & 2 & 6 & 10.8 & Balance \\
\hline $\begin{array}{l}\text { Aver } \\
\text { age }\end{array}$ & 83.4 & $\mathrm{~F}$ & 151.3 & & $\begin{array}{c}11.9 \\
\text { (normal: } \\
9-14 \text { ) }\end{array}$ & $\begin{array}{c}16.8 \\
\text { (normal: } \\
10-16 \text { ) }\end{array}$ & $\begin{array}{c}85.5 \\
\text { (normal: } \\
60-91 \text { ) }\end{array}$ & $\begin{array}{c}5.2 \\
\text { (normal: } \\
-2-3 \text { ) }\end{array}$ & $\begin{array}{c}-\mathbf{6 . 6} \\
\text { (normal: } \\
-5.5-0)\end{array}$ & $\begin{array}{c}\mathbf{9 . 3} \\
\text { (normal: } \\
5.7-8.7 \text { ) }\end{array}$ & $\begin{array}{l}\text { Balance, } \\
\text { Upper body } \\
\text { flexibility }\end{array}$ \\
\hline
\end{tabular}

All participants had the necessary muscle strength and cardiorespiratory endurance to live independently. Therefore, the researchers we planed and analyzed exercise programs to improve 
balance and flexibility as well as strength and aerobic exercise, which are essential exercises suggested by WHO for healthy aging.

\subsection{Research Procedure}

The program was conducted with the person in charge's cooperation by visiting the welfare center in advance. The specific research procedure is shown in [Fig. 1].

For this study, exercise participants were selected through discussions between welfare centers and universities, and they measured their physical strength. After physical strength analysis, the musculoskeletal system and balance were pre-tested, and post-tests were performed after participating in the 15-week program. After that, the data was analyzed and the results and discussions were written.

[Fig. 1] Research Procedure

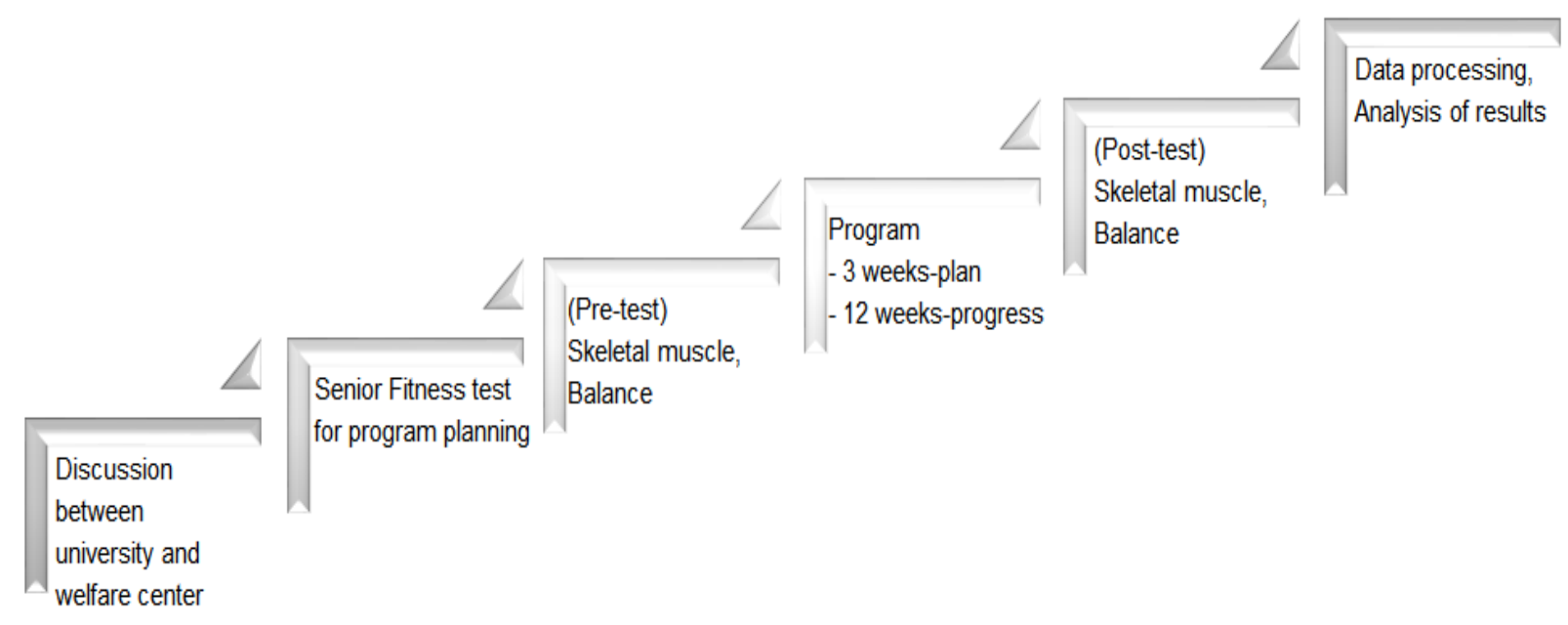

\subsection{Linked Class Exercise Program}

The university-community linked class consisted of 15 weeks of theory and practice ( 3 weeks of program planning and feedback in the classroom, 12 weeks of mock class, actual visiting class, and self-evaluation).

B University students personally visited the A Welfare Center. They performed 60 minutes of warmup exercise (joint exercise, rhythm exercise), main exercise (newsports), and cool-down exercise (stretching, meditation) once a week. The class was conducted as a 1:1 matching activity, and the exercise intensity was moderate (rating of perceived exertion was sweating starting but with no difficulty speaking).

The daily home training was planned for a total of 12 weeks, consisted of primarily stretching and strength training; in other words, this was an exercise at home after exercising together at the center. The specific program is shown in [Table 2].

Linked classes allow students to understand the theory and the field through class planning, preparation, feedback through mock classes, class revision, and actual classes. The elderly individuals living alone can communicate with students through exercise and expect positive physical effects [Fig. 2]. In addition, positive emotional health can be expected, so it is necessary to conduct research that is helpful for emotional health in the future. 
[Table 2] Linked Class - Exercise for Elderly Individuals

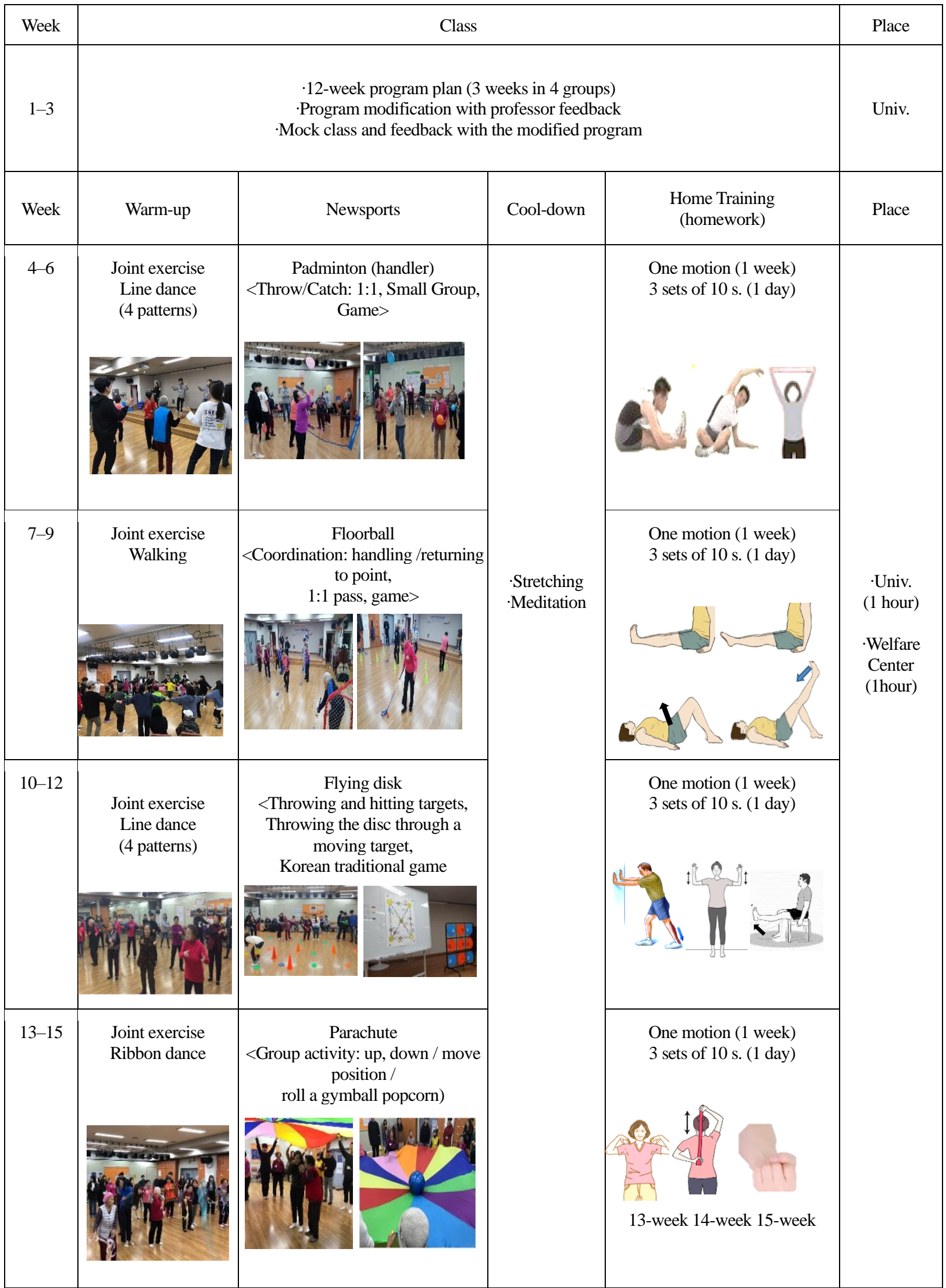




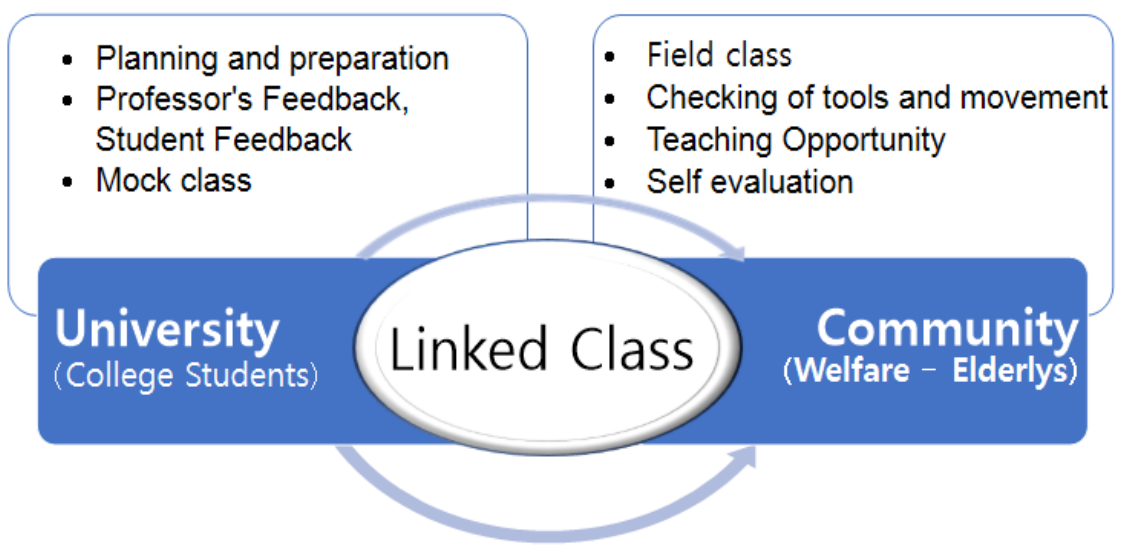

\subsection{Research Tools}

Skeletal muscle mass was measured using an Inbody 120, and lower and upper body muscle strength was measured using the Senior Fitness Test[8]. The balance was measured in the visual system, somatosensory system, and vestibular system. This was based on the sensory integration exercise[9].

Visual system balance was measured with the eyes open and standing on one leg (sec.). The balance measurement for the somatic sensory system was performed by the subject closing their eyes and standing on one leg (sec.). The vestibular system was evaluated using a ball throw and catch on a balance pad (number of times).

\subsection{Analysis}

The collected data were analyzed using IBM SPSS Statistics 25. For general characteristics of the subject, frequency, mean and standard deviation were calculated using descriptive statistics.

To analyze the effect of university-community linked classes, Wilcoxon's signed-ranks test was used to analyze the difference between skeletal muscle (skeletal muscle mass, strength) and balance (vision, somatosensory, vestibular sensation) before and after exercise. To analyze the relationship between skeletal muscle and balance, it was performed Spearmen correlation, a nonparametric test method.

\section{Results and Discussion}

\subsection{Analysis of Skeletal Muscle and Balance Effects Of Elderly Living Alone in a University- Community Linked Class}

After participation in the linked class, skeletal muscle mass, upper and lower body muscle strength were significantly improved in the elderly living alone $(\mathrm{p}<0.05)$ [Table 3].

The elderly performed warm-up exercises and newsports activities planned for strength and aerobic exercise once a week, and home training planned for strength and flexibility exercises every day. The linked class included strength training. The teaching methods according to the level of each older adult through the 1:1 matching program showed positive results. According to Lim and No (2018), muscle strength was the most influential factor for the mobility of older women in rural areas[10]. In a study by Yong-soon (2018), muscle strength loss in the elderly caused severe declines in health-related quality of life[11]. For these reasons, improvement of muscle strength through linked classes can be expected to help the elderly improve their quality of life. 
After participating in the linked class, balance using the vestibular sensory system significantly improved in the elderly living alone $(\mathrm{p}<0.01)$ [Table 3]. Newsports activities were planned as activities requiring hand-eye coordination. Balance depends on the visual system, and lessons using the somatosensory system were designed to be conducted in a safe environment. There was a program in which the participant hits a balloon with a handler, moves a position with a parachute, and dribbles with a floorball stick while walking. Activities using the vestibular sensory system are the most challenging activities. It is thought that vestibular sensory activity is improved by providing a more stable environment than one foot while maintaining balance on the balance pad with both feet.

Because older adults generally have many balance problems related to changes in the vestibular system instead of the visual or somatosensory systems, the results of the present study showed that the linked class could improve the vestibular sensory system. There was a positive effect on muscles and balance necessary for activities of daily living among the elderly individuals living alone.

[Table 3] Analysis of the effects of skeletal muscle and balance in the elderly living alone

\begin{tabular}{|c|c|c|c|c|c|}
\hline & & \multicolumn{2}{|c|}{ Median (range) } & \multirow{2}{*}{$\mathrm{Z}$} & \multirow{2}{*}{$\mathrm{p}$} \\
\hline & & pre & post & & \\
\hline \multirow{3}{*}{$\begin{array}{c}\text { Skeletal } \\
\text { muscle }\end{array}$} & Skeletal muscle mass $(\mathrm{kg})$ & $18.0(10.0)$ & $18.3(10.4)$ & -2.825 & $0.005^{* *}$ \\
\hline & Lower muscle strength (number of times) & $11.0(7.0)$ & $14.0(7.0)$ & -2.840 & $0.005^{* *}$ \\
\hline & Upper muscle strength (number of times) & $15.0(11.0)$ & $20.0(11.0)$ & -2.677 & $0.007 * *$ \\
\hline \multirow{5}{*}{ Balance } & (Left) Visual system (sec) & $4.0(8.0)$ & $4.0(18.0)$ & -0.256 & 0.798 \\
\hline & (Right) Visual system (sec) & $4.0(14.0)$ & $5.0(9.0)$ & -0.934 & 0.350 \\
\hline & (Left) Somatosensory system (sec) & $2.9(6.5)$ & $2.5(3.0)$ & -1.072 & 0.284 \\
\hline & (Right) Somatosensory system (sec) & $3.0(8.7)$ & $2.8(5.0)$ & -0.299 & 0.765 \\
\hline & Vestibular system (number of times) & $19.0(38.0)$ & $33.0(54.0)$ & -2.420 & $0.016^{*}$ \\
\hline
\end{tabular}

\subsection{The Relationship Between Skeletal Muscle and Balance in Elderly Individuls Living Alone Participating in a University-Community Linked Class}

When analyzing the correlation between skeletal muscle and balance in the elderly individuls living alone, we found a positive correlation between lower muscle strength and balance using the visual system (balancing with the eyes open). In other words, when the subject had eyes open and balanced on one foot, they required lower body strength to maintain good balance.

Upper body strength showed a positive correlation when balancing with the right foot using the visual and somatosensory systems. This result suggests that older adults show positive effects when balancing with the right foot (opened and closed eyes) when using the upper body to balance.

In other words, gradual balance training on solid ground is required not only when eyes are open but also in dark environments or when vision is reduced or obstructed. This result suggests that it is 
The Effect of Participation in a University-Community Linked Class on Skeletal Muscle and Balance of Elderly Individuals Living Alone

necessary to improve upper body strength.

Skeletal muscle mass and the vestibular sensory system showed a positive correlation as muscle strength decreases due to aging and disease; balance using the vestibular sensory system may also decrease. It is difficult to balance using the vestibular sensory system because the frequency of participation in physical activities that entail moving the head mediated by muscle strength decreases rapidly. In other words, the increase in skeletal muscle mass suggests that the balance using the vestibular sensory system can be improved.

Movement involving the vestibular sensory system is more complicated than movement using the visual and somatosensory systems; however, balance using the vestibular sensory system can be improved if skeletal muscle mass increases. Balance using the vestibular system is necessary for independent performance of activities of daily living such as going to the bathroom at night, walking on uneven surfaces, and washing hair.

[Table 4] The Relationship between Skeletal Muscle and Balance in the Elderly Living Alone

\begin{tabular}{|c|c|c|c|c|c|c|}
\hline & & \multicolumn{5}{|c|}{ Balance } \\
\hline & & $\begin{array}{c}\text { Left } \\
\text { Visual system } \\
(\mathrm{sec}) \\
\end{array}$ & $\begin{array}{c}\text { Right } \\
\text { Visual system } \\
(\mathrm{sec}) \\
\end{array}$ & $\begin{array}{c}\text { Left } \\
\text { Somatosensory } \\
\text { system (sec) }\end{array}$ & $\begin{array}{c}\text { Right } \\
\text { Somatosensory } \\
\text { system }(\mathrm{sec})\end{array}$ & $\begin{array}{r}\text { Vestibular system } \\
\text { (number of times) }\end{array}$ \\
\hline \multirow{3}{*}{$\begin{array}{l}\text { Skeletal } \\
\text { muscle }\end{array}$} & $\begin{array}{l}\text { Skeletal muscle mass } \\
\qquad(\mathrm{kg})\end{array}$ & 0.536 & 0.541 & 0.356 & 0.060 & $0.782 * *$ \\
\hline & $\begin{array}{l}\text { Lower muscle strength } \\
\text { (number of times) }\end{array}$ & $0.614 *$ & $0.772 * *$ & 0.445 & 0.540 & 0.422 \\
\hline & $\begin{array}{l}\text { Upper muscle strength } \\
\text { (number of times) }\end{array}$ & 0.601 & $0.735^{*}$ & 0.575 & $0.734 *$ & 0.125 \\
\hline
\end{tabular}

$* \mathrm{p}<.05, * * \mathrm{p}<.01$

\section{Conclusion}

The purpose of this study was to investigate the effect of participation in university-community linked class among the elderly living alone on skeletal muscle and balance related to daily living.

The study subjects were 11 elderly living alone at a welfare center. The university-community linked class lasted 15 weeks. The class was consisted of moderate-intensity newsports(60 minutes once per week), and flexibility and strength-based home training(five times per week).

As a result, skeletal muscle mass, upper and lower body muscle strength in the elderly subjects all improved, and balance using the vestibular sensory system also improved. There was a positive correlation between balance using the visual system and lower body muscle strength. There was also a positive correlation between upper body muscle strength when holding balance with the right foot using the visual and somatosensory systems. We found a significant positive correlation between vestibular sensation and skeletal muscle mass. Through this program, skeletal muscle and balance in the elderly living alone improved.

In conclusion, the university-community linked class in this study was planned as a warm-up exercise, new sports cool-down exercise, and daily home training class. It was found that the university-community linked class improved physically(skeletal muscle and balance) for the elderly living alone. This result implies the necessity of continuously linked-class as it can bring about fall prevention and activities of daily living. To improve health status, it is necessary to provide ways for the elderly to increase their participation in education and change their perceptions[12]. It has been shown that elderly education is becoming an essential part of life[13]. In other words, it suggests the 
necessity of continuous university-community linked class.

This study is considered to have provided an opportunity to help active participation and emotional stability through a 1:1 matching class for students and the elderly living alone. Therefore, future studies should focus on ongoing linked classes for the elderly (qualitative studies for in-depth analysis of physical and mental effects) and university students (class satisfaction, field opportunities, and employment linkage).

[Fig. 3] Conclusion about Linked Class

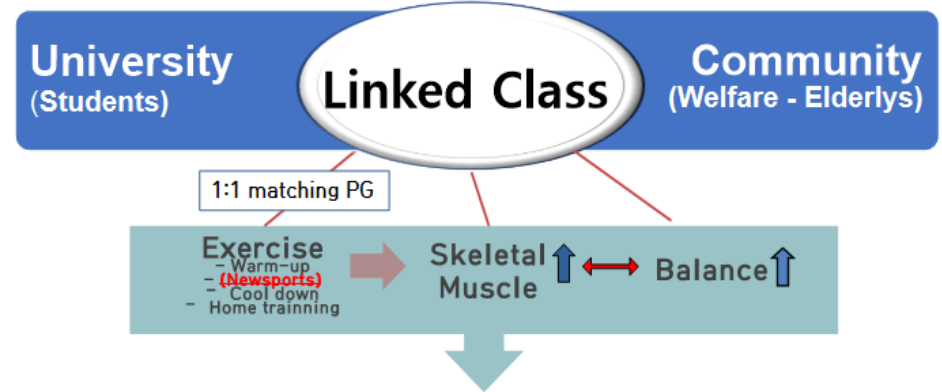

\title{
Need for continuous research on linked classes
}

\author{
(ADL $\uparrow \quad$ Fall Prevention $\uparrow \quad$ Physical \& Emotional health $\uparrow)$
}

\section{References}

[1]https://kosis.kr/statHtml/statHtml.do?orgId=101\&tblId=DT_1BPB003\&vw_cd=MT_ZTITLE\&list_id=A41_30\&seqN $\mathrm{o}=\&$ lang_mode $=$ ko\&language=kor\&obj_var_id=\&itm_id=\&conn_path=MT_ZTITLE, Jan 21 (2021)

[2]https://kosis.kr/statHtml/statHtml.do?orgId=101\&tblId=DT_1BPA201\&vw_cd=MT_ZTITLE\&list_id=A41_10\&seqN o=\&lang_mode=ko\&language=kor\&obj_var_id=\&itm_id=\&conn_path=MT_ZTITLE, Jan 21 (2021)

[3]https://kosis.kr/statHtml/statHtml.do?orgId=101\&tblId=DT_1YL12701\&vw_cd=MT_GTITLE01\&list_id=102\&seqN o=\&lang_mode=ko\&language=kor\&obj_var_id=\&itm_id=\&conn_path=MT_GTITLE01, Jan 21 (2021)

[4] M. S. Song, S. J. Boo, The Effect of an Exercise Program for Preventing Urinary Incontinence among CommunityDwelling Elderly Females Living Alone, Journal of Korean Public Health Nursing, (2016), Vol.30, No.2, pp. 247258, https://doi.org/10.5932/JKPHN.2016.30.2.247

[5] M. S. Baik, J. H. Kim, A Study on Development Trend and Commercialization of Elderly-friendly Paid Welfare Houses for Seniors, International Journal of Social Welfare Promotion and Management, (2017), Vol.4, No.1, pp.1-6.

[6] http://dongascience.donga.com/news.php?idx=25156, Nov 19 (2018)

[7] S.S. Shim, J. H. Yoo, A Study on the Leisure Satisfaction of the Aged Participation in New Sports, The Korean Society of Sports Science, (2010), Vol.19, No.2, pp.299-309, UCI : G704-001369.2010.19.2.021

[8] R.E. Riki, C.J. Jones, Senior Fitness Test Manual (2nd ed), Human Kinetics, (2012), pp.11-53.

[9] Elizabeth Best-Martini, Kim A. Jones-diGenova, Exercise for Frail Elders (2nd ed.), Human Kinetics, (2014)

[10] E. Lim, J. Noh, Factors Influencing the Mobility of Malnourished Rural Elderly Women, International Journal of Elderly Welfare Promotion and Management, (2018), Vol.2, No.1, pp.15-20.

[11] Y. S. Park, Effect of dynapenia on the health-related quality of life of older people in Korea, Graduate School, 
The Effect of Participation in a University-Community Linked Class on Skeletal Muscle and Balance of Elderly Individuals Living Alone

Hallym University, Doctor dissertation, (2018)

[12] O. Ahn, S. Choi, Predictors of Health Inequality of Elderly and One-Person Households 2010-2015, International Journal of Elderly Welfare Promotion and Management, (2018), Vol.2, No.1, pp.27-32.

[13] Z. Xichen, L. Mengnan, Analysis of the Function of Elder Education to Continue Socialization of the Elderly, International Journal of Elderly Welfare Promotion and Management, (2020), Vol.4, No.1, pp.1-6. 